\title{
Morphology and proportion of inner cell mass of bovine blastocysts fertilized in vitro and in vivo
}

\author{
S. Iwasaki, N. Yoshiba*, H. Ushijima†, S. Watanabeł and T. Nakahara \\ NODAI Research Institute and $\ddagger$ Department of Animal Science, Tokyo University of Agriculture, \\ Setagaya-ku, Tokyo 156, Japan; * Saitama Prefectural Livestock Research Center, Oosato-gun, \\ Saitama 360-01, Japan; and +Chiba Prefectural Livestock Research Center, Inba-gun, \\ Chiba 289-11, Japan
}

\begin{abstract}
Summary. The morphology and proportion of inner cell mass (ICM) of bovine blastocysts cultured in vitro or in vivo in rabbit oviducts after in-vitro fertilization of in-vitro matured follicular oocytes were compared with those of blastocysts fertilized in vivo by a differential fluorochrome staining technique. The delineation of each ICM cell was improved by the transfer of embryos derived from in-vitro fertilization to a rabbit oviduct although the cell-cell contacts of ICM cells were not as tight as those from in-vivo fertilization. The proportions (15.8 and 14.9\%) of ICM in blastocysts cultured in vitro at early and expanded stages were significantly lower than those cultured in rabbit oviducts after in-vitro fertilization and fertilized in vivo. These results show that the transfer of bovine embryos derived from in-vitro fertilization to the rabbit oviduct increased the proliferation of ICM cells to the level of embryos fertilized in vivo although the cell-cell contact of ICM cell is not improved by the process.
\end{abstract}

Keywords: cattle; blastocysts; inner cell mass; in-vitro fertilization

\section{Introduction}

An in-vitro culture system has been established to mature in vitro bovine embryos obtained from in-vitro fertilized oocytes collected from ovaries (Xu et al., 1987; Fukuda et al., 1988; Goto et al., 1988). In general, it has been suggested that the pregnancy rate of bovine embryos derived from in-vitro fertilization was lower than that for those recovered in vivo. However, little is known concerning what the main factor affecting the low quality of blastocysts derived from in-vitro fertilization might be.

Papaioannou \& Ebert (1986) suggested that the cell number may be a valid indicator of the viability of preimplantation embryos although morphological criteria alone are poor indicators. In fact, Wurth et al. (1988) showed that the mean cell number of blastocysts recovered in vivo decreased with decreasing quality. Early pig blastocysts transferred to the mouse oviduct showed a 2 -fold increase in cell division over comparable blastocysts grown in vitro (Ebert \& Papaioannou, 1989). A similar tendency was observed in the bovine embryos derived from in-vitro fertilization and transferred to a rabbit oviduct (Iwasaki \& Nakahara, 1990). Handyside \& Hunter (1984) established the double dye technique for differential inner cell mass (ICM) and trophectoderm cell counts of mouse blastocysts. That is, trophectoderm nuclei were labelled in situ with propidium iodide by permeabilizing the cells using species-specific antibody-mediated complement lysis and the intact ICM nuclei were only labelled with bisbenzimide. As a result, the nuclei of the two cell types can be distinguished by fluorescence microscopy: the outer trophectoderm nuclei appear pink and the ICM nuclei blue. By using this technique, Papaioannou \& Ebert (1988) showed that the proportion of ICM cells in pig blastocysts formed in vitro was within the normal range. 
In the present paper, bovine blastocysts were prepared by in-vitro fertilization of in-vitro matured follicular oocytes collected from ovaries and followed by culture in vitro or in rabbit oviducts or prepared by in-vivo fertilization. Total cell number, the morphology, and the proportion of ICM of blastocysts derived from the three culture systems were investigated to compare the qualities of embryos.

\section{Materials and Methods}

Preparation of blastocysts cultured in vitro or in rabbit oviducts after in-vitro fertilization. Bovine blastocysts were obtained from two different culture systems after in-vitro fertilization; (I) in-vitro development by co-culture with cumulus cells and, (II) in-vivo culture in a rabbit oviduct. Briefly, follicular oocytes were collected into PBS with $0 \cdot 3 \%$ BSA (Fraction V, Seikagaku Kogyo, Tokyo, Japan) at $38^{\circ} \mathrm{C}$ from the ovaries of Holstein cows obtained from a slaughterhouse and were immediately matured and fertilized in vitro by the method of Iwasaki et al. (1988) with minor modification. That is, the sperm concentration was adjusted to $25 \times 10^{6} / \mathrm{ml}$ and treated with $0 \cdot 1 \mu \mathrm{M}$-ionophore A23187 (Calbiochem-Behring Corp., La Jolla, CA, USA) for $1 \mathrm{~min}$, followed by incubation with $2 \mathrm{mg}$ BSA (crystallized and lyophilized, Sigma, St Louis, MO, USA)/ml. After $8 \mathrm{~h}$ of sperm-egg incubation, the oocytes were transferred to a development medium (25 mM Hepes-buffered TCM 199 supplemented with $10 \%$ fetal calf serum, $0.5 \mathrm{~mm}$-sodium pyruvate and antibiotics). For in-vitro culture, the oocytes after sperm-egg incubation were cultured in vitro in development medium continuously, with exchange of medium every $48 \mathrm{~h}$. Under these conditions, cumulus cells surrounding the oocyte formed a monolayer on the surface of the culture dish. The development of emiryos was observed every 24 or $48 \mathrm{~h}$ and blastocysts at early, expanded and hatched stages were obtained 8-12 days after sperm-egg incubation. About $12 \%$ of 4-cell-stage embryos developed in vitro to the blastocyst stage but the compaction of blastomeres at the morula stage was not clear. Hatching was observed at 9-11 days after sperm-egg incubation.

Alternatively, at $40-42 \mathrm{~h}$ after sperm-egg incubation, 4- to 8-cell embryos were transferred surgically to a rabbit oviduct for in-vivo culture. After 5 days, the embryos were recovered surgically from the rabbit oviduct and further cultured in vitro in the development medium described above. About $72-97 \%$ of the bovine embryos were recovered from the rabbit oviduct and about $27-50 \%$ of these recovered embryos were at morula to expanded blastocyst stages. Embryos at the morula stage showed a clear compaction of blastomeres and hatching was observed 1-3 days after in-vitro culture in the development medium mentioned above. Only about half of the embryos hatched from the zona pellucida although they expanded to the size of hatched embryos derived from in-vivo fertilization.

Preparation of bovine blastocysts fertilized in vivo. Holstein heifers in the mid-luteal phase of the cycle were given FSH (Antrin, Denka Pharma., Kawasaki, Japan) twice daily for 3 days in decreasing doses: $5 / 5 \mathrm{mg}, 4 / 4 \mathrm{mg}$ and $3 / 3 \mathrm{mg}$, respectively and $1.5 \mathrm{mg}$ PGF-2 $\alpha$ (Pronalgon, Takeda Pharm., Osaka, Japan) twice on the last day of FSH injection. At 36,48 and $60 \mathrm{~h}$ after the treatment, the animals were artificially inseminated with two straws of frozen semen from a proven fertile bull. Embryos were collected at Day 7 after oestrus by non-surgical flushing with Dulbecco's PBS including 0.3\% BSA, streptomycin and penicillin. These recovered embryos were at compact morula and early blastocyst stages and hatching was observed at 2-3 days after in-vitro culture in the development medium mentioned above.

Development of a rabbit anti-bovine spleen cell antiserum. This antiserum was developed for immunosurgery of bovine embryos for the purpose of making differential cell counts of the ICM and trophectoderm of the blastocysts. Briefly, spleen cells from adult cattle were prepared at a concentration of $2 \times 10^{8} / \mathrm{ml}$ in Ca- and $\mathrm{Mg}$-free PBS and $1.6 \mathrm{ml}$ was injected intravenously into Japanese White female rabbits every 7 days for 5 weeks. Booster injections were given 21 days later and the rabbit was then killed and exsanguinated. Blood samples for antibody testing were taken before booster injection. Serum was collected, heat-inactivated for complement and tested for antibody titres and specificity using unfertilized oocytes and blastocysts from cattle.

Immunosurgery and double-dye technique for differential ICM/trophectoderm cell counts of blastocysts. Differential cell counts of blastocysts were carried out by the method of Papaioannou \& Ebert (1988) with minor modification. Briefly, the embryos were treated with $0.5 \%$ pronase (Actinase E, Kaken Kagaku, Tokyo, Japan) in PBS for 3-8 min to dissolve the zona pellucida. They were then incubated with $10 \%$ rabbit anti-bovine spleen cell antiserum for $30 \mathrm{~min}$ at $39^{\circ} \mathrm{C}$. Subsequently, the embryos were washed 5 times with TCM 199 containing $10 \%$ fetal calf serum and antibiotics and then incubated with $10 \%$ guinea-pig serum containing propidium iodide (Sigma) and bisbenzimide (Hoechst 33342, Sigma) at a final concentration of $10 \mu \mathrm{g} / \mathrm{ml}$ of complement solution for $30 \mathrm{~min}$ at $39^{\circ} \mathrm{C}$. Finally, the embryos were washed in PBS with 0.3\% BSA and squashed on a slide glass.

The embryo preparations were examined using a Nikon fluorescent microscope with an excitation filter of $365 \mathrm{~nm}$ and a barrier filter of $420 \mathrm{~nm}$. This resulted in bisbenzimide-stained nuclei (vital) fluorescing blue and nuclei (nonvital) stained with both fluorochromes fluorescing pink. The tightness of cell-cell contact of ICM cells was assessed by a comparison of the relative distance between cells.

Statistics. Comparisons of data in the present paper among developmental stages, the quality of the embryos and the 3 culture systems were made by $t$ tests. 


\section{Results}

\section{Anti-bovine spleen cell antiserum}

At dilutions of 1:10 and 1:5, the antiserum was effective for complement mediated cell lysis of bovine oocytes and trophectoderm, but at dilutions of 1:20 and 1:40, cell lysis was only partly affected and was unaffected at 1:80 and 1:160. Consequently, rabbit serum was used at $10 \%$ for immunosurgery and differential staining.

\section{Morphology and proportion of ICM in blastocysts derived from different culture systems}

The blue ICM nuclei and pink trophectoderm nuclei could be easily distinguished by the double-dye technique (Fig. 1). The nuclei of each ICM cell from in-vivo and in-vitro-in-vivo culture systems were sharply delineated (Figs 1a,b) but the ICM cells from the in-vitro culture system were partly distorted (Fig. 1c). The cell-cell contact of ICM from in-vivo fertilization was tight, while that of the ICM from the two culture systems followed by in-vitro fertilization was less tight.
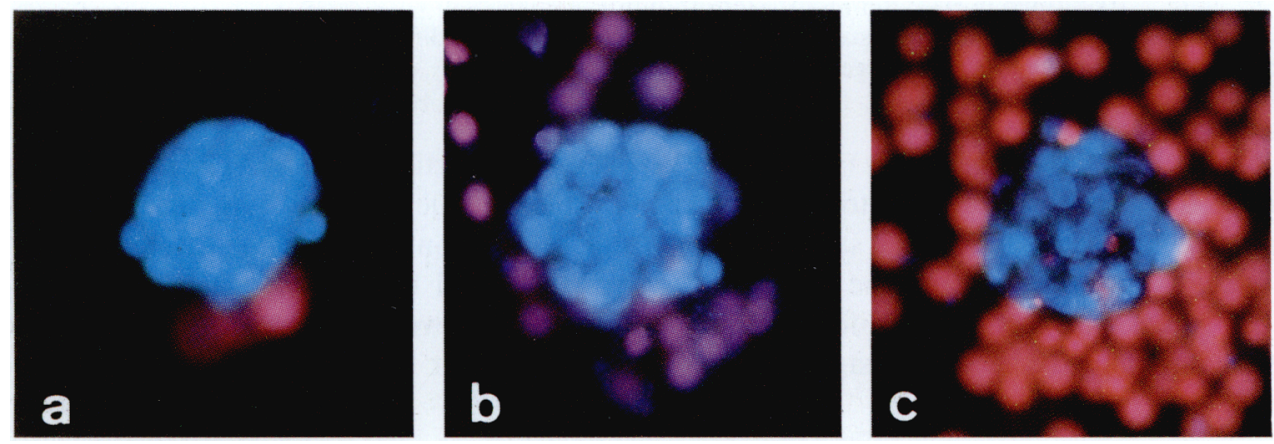

Fig. 1. Fluorescence micrographs of the ICM and trophectoderm nuclei of bovine expanded blastocysts derived from various culture systems by labelling with bisbenzimide and propidium iodide (blue, ICM nuclei; pink, trophectoderm nuclei). $\times 200$. (a) Fertilized and developed in vivo (control). (b) Cultured in a rabbit oviduct after in-vitro fertilization. (c) Cultured in vitro after in-vitro fertilization.

Total cell number and the proportion of ICM cells at each stage of blastocyst development after culture are summarized in Table 1. In some blastocysts, especially from the in-vitro culture system, the cell number of the ICM was not defined because the morphology was not good and there were some embryos with no ICM nuclei fluorescing blue. Furthermore, some embryos (especially at the hatched stage) were found with only a few live cells fluorescing blue and most degenerated cells fluorescing pink, but with many trophectoderm cells showing a normal clear shape and fluorescing pink. The data from these embryos were omitted from the table. Total cell number (44 and 77) of blastocysts cultured in vitro at early and expanded stages was significantly lower than those of embryos cultured in the rabbit oviduct or fertilized in vivo (63 and 113), but reached the same level as the other two culture systems at the hatched stage. Total cell number of blastocysts cultured in rabbit oviducts was almost the same as that of blastocysts fertilized in vivo except for those at the expanded stage.

The number of ICM cells (8 and 11) and their proportion (15.8 and 14.9\%) in blastocysts cultured in vitro at early and expanded stages were significantly lower than those of embryos cultured in rabbit oviducts $(23.4$ and $20.8 \%)$ or fertilized in vivo $(25.0$ and $20.9 \%)$. At the hatched stage, the number of ICM cells (16) and their proportion (12.8\%) of blastocysts cultured in vitro 
Table 1. Total cell number and proportion of inner cell mass (ICM) of bovine blastocysts derived from each culture system at each stage

\begin{tabular}{|c|c|c|c|c|}
\hline \multirow{2}{*}{$\begin{array}{l}\text { Culture } \\
\text { system }\end{array}$} & \multirow{2}{*}{$\begin{array}{c}\text { No. of } \\
\text { embryos }\end{array}$} & \multirow{2}{*}{$\begin{array}{c}\text { Total } \\
\text { cell } \\
\text { no. }\end{array}$} & \multicolumn{2}{|c|}{ ICM } \\
\hline & & & Cell no. & Proportion $(\%)$ \\
\hline \multicolumn{5}{|l|}{ Early } \\
\hline IVF-in vitro* & 56 & $44 \pm 18^{\mathrm{a}}$ & $8 \pm 5^{a}$ & $15.8 \pm 7.8^{\mathrm{a}}$ \\
\hline IVF-in vivo ${ }^{\dagger}$ & 18 & $75 \pm 27^{b}$ & $19 \pm 13^{b}$ & $23 \cdot 4 \pm 11 \cdot 4^{b}$ \\
\hline In vivo & 21 & $63 \pm 19^{b}$ & $16 \pm 8^{b}$ & $25 \cdot 0 \pm 8 \cdot 3^{b}$ \\
\hline \multicolumn{5}{|l|}{ Expanded } \\
\hline IVF-in vitro & 86 & $77 \pm 33^{\mathrm{a}}$ & $11 \pm 7^{\mathrm{a}}$ & $14.9 \pm 6 \cdot 9^{\mathrm{a}}$ \\
\hline IVF-in vivo & 30 & $89 \pm 26^{\mathrm{b}}$ & $18 \pm 8^{\mathrm{b}}$ & $20.8 \pm 7.6^{\mathrm{b}}$ \\
\hline In vivo & 11 & $113 \pm 23^{c}$ & $23 \pm 7^{b}$ & $20 \cdot 9 \pm 5 \cdot 4^{b}$ \\
\hline \multicolumn{5}{|l|}{ Hatched } \\
\hline IVF-in vitro & 31 & $121 \pm 46^{\mathrm{a}}$ & $16 \pm 8^{\mathrm{a}}$ & $12 \cdot 8 \pm 5 \cdot 0^{\mathrm{a}}$ \\
\hline IVF-in vivo & 6 & $122 \pm 40^{\mathrm{a}}$ & $21 \pm 7^{a b}$ & $17 \cdot 2 \pm 2 \cdot 8^{\mathrm{a}}$ \\
\hline In vivo & 7 & $113 \pm 29^{\mathrm{a}}$ & $31 \pm 12^{\mathrm{b}}$ & $27 \cdot 2 \pm 7 \cdot 2^{b}$ \\
\hline
\end{tabular}

was significantly lower than those ( 31 and $27 \cdot 2 \%$ ) of embryos fertilized in vivo. The number of ICM cells and their proportion in blastocysts cultured in rabbit oviducts were not significantly different from those fertilized in vivo at all stages except for the proportion at the hatched stage.

These results showed that the transfer of embryos derived from in-vitro fertilization to the rabbit oviduct increased the proliferation of ICM cells to the level of embryos fertilized in vivo at early and expanded blastocyst stages although transfer did not improve the cell-cell contacts of ICM cells.

\section{Discussion}

The present study is the first attempt to describe the morphology and the proportion of ICM cells in bovine blastocysts fertilized in vivo and fertilized in vitro using in-vitro matured follicular oocytes followed by culture in vitro or in a rabbit oviduct. The differential labelling technique for ICM and trophectoderm nuclei in situ has two important advantages for the determination of cell numbers of ICM and trophectoderm and the analysis of regional interaction (Handyside \& Hunter, 1984).

The morphological observation in this study presented the following two important facts. (1) The delineation of each blastomere of ICM cells in bovine blastocysts derived from in-vitro fertilization of in-vitro matured oocytes was improved by the transfer of the embryos to the rabbit oviduct from the 4-cell stage. (2) The cell-cell contacts of ICM cells in bovine blastocysts derived from in-vivo fertilization were tighter than those from in-vitro fertilization followed by culture in vitro and in a rabbit oviduct. It has previously been shown that the asynchrony of the compaction in 8-cell blastomeres is important for the subsequent generation of two types of cell lineage in the morula, which give rise to the trophectoderm and ICM of the blastocyst respectively (Johnson \& Ziomek, 1981; Fehilly et al., 1984). Bovine blastocysts cultured in vitro do not show clear compaction of blastomeres at the morula stage although such compaction is observed in blastocysts cultured in a rabbit oviduct after in-vitro fertilization. Accordingly, the cell-cell contacts of ICM cells may be related to the condition of compaction of blastomeres at the morula stage.

It is known that there are many factors such as calcium ions (Ducibella \& Anderson, 1975), microtubules (Maro \& Pickering, 1984), myosin (Sobel, 1983) and protein kinase C (Bloom, 1989) 
influencing the cell-cell contacts during compaction. Ducibella \& Anderson (1975) demonstrated that the calcium ion threshold for compaction is approximately $0 \cdot 1-0.2 \mathrm{~mm}$ and may be required for normal intercellular adhesions. But this factor may not influence the cell-cell contacts of ICM cells in bovine blastocysts cultured in vitro because the culture medium includes a concentration of 1.8 mm-calcium chloride. Ducibella \& Anderson (1975) also demonstrated that compaction may be due to a change in cell-cell adhesion during the mouse 8-cell stage or a change in the deformability of the membrane or both. Although the mechanism in compaction could not be directly applied in our study, detailed observation by electron microscopy and further biochemical and immunohistochemical analyses will be required to compare the morphology of ICM cells in bovine blastocysts derived from various culture systems after in-vitro fertilization.

In the present study, a relatively large variation was found in the data within a category. This may be caused by a variation in the quality of embryos. That is, an embryo developing quickly to the blastocyst stage was of a higher quality than one that developed later although these were placed in the same category. In addition, ICM cell number of embryos cultured in a rabbit oviduct is not consistent although those from the other two origins increased gradually with advance in development (Table 1). Most embryos recovered from a rabbit oviduct had reached the expanded stage and embryos in the early blastocyst stage category had advanced to a stage just before the expanded stage. This is the reason for high numbers of total and ICM cells of early blastocysts in this culture system. About half of the embryos cultured in a rabbit oviduct could not hatch from the zona pellucida. This may be caused by the presence of a mucin layer originated from the rabbit oviduct.

The proportions of ICM cells in blastocysts from in-vitro fertilization decreased gradually with advance in development in both culture systems, although those from the in-vivo fertilization were identical in the early and hatched stages. This fact shows that some parts of ICM cells in blastocysts derived from in-vitro fertilization initiated the degradation of cells. The culture of bovine embryos in rabbit oviducts increased not only the total cell number but also the proportion of ICM cells of blastocysts cultured in vitro after in-vitro fertilization except for those at the hatched stage. These results indicate that the transfer of embryos to the rabbit oviduct improved cell division in the ICM more than in trophectoderm cells. It was clearly demonstrated that the reduced proportion of the ICM expresses a reduced viability (Willadsen \& Polge, 1981). Consequently, the reduced cell proliferation of ICM cells may be the cause of the low pregnancy rates of blastocysts derived from in-vitro fertilization.

It is concluded that the differential labelling of ICM and trophectoderm nuclei in situ is a very useful technique to evaluate embryo qualities, and that in-vitro culture after in-vitro fertilization of in-vitro matured oocytes is still not a completely satisfactory system for the development of bovine embryos up to the blastocyst stage.

This research was supported by a grant from the Itoh Foundation.

\section{References}

Bloom, T.L. (1989) The effects of phorbol ester on mouse blastomeres: a role for protein kinase $\mathrm{C}$ in compactin. Development 106, $159-171$.

Ducibella, T. \& Anderson, E. (1975) Cell shape and membrane changes in the eight-cell mouse embryos: prerequisites for morphogenesis of the blastocyst Devl Biol. 47, 45-58.

Ebert, K.M. \& Papaioannou, V.E. (1989) In vivo culture of embryos in the immature mouse oviduct. Theriogenology 31, 299-308.

Fehilly, C.B., Willadsen, S.M. \& Tucker, E.M. (1984) Interspecific chimaerism between sheep and goat. Nature, Lond. 307, 634636.
Fukuda, Y., Ichikawa, M., Naito, K. \& Toyoda, Y. (1988) Normal development of bovine oocytes matured, fertilized, and cuitured with cumulus cells in vitro. Proc. Ilth Int. Congr. Anim. Reprod. \& A.I., Dublin, Vol. 3, No. 327.

Goto, K., Kajihara, Y., Kosaka, S., Koba, M., Nakanishi, Y. \& Ogawa, K. (1988) Pregnancies after co-culture of cumulus cells with bovine embryos derived from in-vitro fertilization of in-vitro matured follicular oocytes. J. Reprod. Fert. 83, 753-758.

Handyside, A.H. \& Hunter, S. (1984) A rapid procedure for visualising the inner cell mass and trophectoderm nuclei of mouse blastocysts in situ using poly- 
nucleotide-specific fiuorochromes. J. exp. Zool. 231, $429-434$.

Iwasaki, S. \& Nakahara, T. (1990) Cell number and incidence of chromosomal anomalies in bovine blastocysts fertilized in vitro followed by culture or in vivo in rabbit oviducts. Theriogenology 33, 669-675.

Iwasaki, S., Shioya, Y., Masuda, H., Hanada, A. \& Nakahara, T. (1988) Sex ratio of early embryos fertilized in vitro with spermatozoa separated by Percoll. Theriogenology 30, 1191-1198.

Johnson, M.H. \& Ziomek, C.A. (1981) The foundation of two distinct cell lineages within the mouse morula. Cell 24, 71-80.

Maro, B. \& Pickering, S. (1984) Microtubules influence compaction in preimplantation mouse embryos. $J$. Embryol. exp. Morph. 84, 217-232.

Papaioannou, V.E. \& Ebert, K.M. (1986) Development of fertilized embryos transferred to oviducts of immature mice. J. Reprod. Fert. 76, 603-608.
Papaioannou, V.E. \& Ebert, K.M. (1988) The preimplantation pig embryo: cell number and allocation to trophectoderm and inner cell mass of the blastocyst in vivo and in vitro. Development 102, 793-803.

Sobel, J.S. (1983) Cell-cell modulation of myosin organization in the early mouse embryo. Devl Biol. 100, 207-213.

Willadsen, S.M. \& Polge, C. (1981) Attempts to produce monozygotic quadruplets in cattle by blastomere separation. Vet. Rec. 108, $211-213$.

Wurth, Y.A., van der Zee-Kotting, W., Kruip, Th.A.M., Dieleman, S.J. \& Bevers, M.M. (1988) Relation between macroscopic qualification of bovine embryos and number of blastomeres. Proc. 11th Int. Congr. Anim. Reprod. \& A.I., Dublin, Vol. 3, No. 352.

Xu, K.P., Greve, T., Callesen, H. \& Hyttel, P. (1987) Pregnancy resulting from cattle oocytes matured and fertilized in vitro. J. Reprod. Fert. 81, 501-504.

Received 15 January 1990 